\title{
Analysis of Problems in Professional Development of College Teachers and Strategy Research
}

\author{
Jianhong Ma \\ College of Education, Ningxia University, Yinchuan, 750021, China
}

Keywords: college teachers, professional development, problem analysis, improvement measures

\begin{abstract}
At present, Chinese colleges have a series of prominent problems in terms of teachers' professional development, mainly including inexplicit professional development planning, inadequate professional development training and insufficient self-cognition of teachers etc. How to seek an effective way to develop professional development education facing existing problems has become a primary issue in professional development of college teachers. On this basis, this paper studies on issues related to modern professional concept and professional planning.
\end{abstract}

\section{Introduction}

Under modern education system, colleges are the cradle of talents, and play an important role of cultivating high-quality talents for social development, and play an irreplaceable core role in enhancing scientific and technological research and development strength and promoting scientific and technological progress. Teachers determine directly the improvement of college teaching quality and students' qualities. Current reality is that low professional development degree of college teachers has seriously hindered further improvement of college education teaching quality. In particular, the rise of information technology and new teaching model of network multimedia brings unprecedented challenges to teaching of college teachers, and affects profoundly college teachers' change of their qualities, teaching concepts and teaching model. On the other hand, college enrollment expansion brings burden to teachers, so that teachers have limited energy. How to teach more scientifically and efficiently in a limited time, improve professional level of college teachers and realize professional development has become the only way.

\section{The connotation of professional development of college teachers}

\section{Teachers' professional development}

The main connotation of teachers' professional development refers that teachers exercise and improve their professional teaching skills through continuous efforts under a specific external environment, strengthen relevant skills and accumulate professional knowledge constantly during this process, and thus get professional development. Essentially speaking, teachers' professional development refers to a process that teachers obtain improvement and development through skill training and accumulation of professional knowledge in work.

\section{Teachers' career development}

Professional development of college teachers cannot be separated from their career development. Teachers will not truly get professional development without scientific planning for professional career. Teachers' career development, just as its name implies, refers to the development process of targeted and planned exercise and improvement of professional knowledge and skills to achieve specific professional goals. Career development stresses subjective initiative of individuals in achieving professional goals. Individuals could fully release their potential through continuous efforts, achieve greater development in professional career and bring organizational performance active and positive motivation.

\section{Research significance of college teachers' professional development}

As the most important transmitters of human civilization, college teachers shoulder very important 
cultural transmission task. Meanwhile, they are also important enlightening people of various ideas and thoughts, and have an influence on world outlook and values of young students during teaching by interpreting civilization, and also exercise and train young students to improve scientific research skills. On the other hand, as advanced intellectuals in the society, they play a direct role in social development as intellectual elite. With continuous social development, there are growing requirements for people's knowledge and skills in the society, which requires constant reform of talent education in order to keep up with the pace of development of the times. College teachers are an important core of reform forces, and the development of social culture will be hindered if teachers' professional development is lagged behind the development of the times.

This phenomenon is particularly common in recent years, and plays a significantly positive role as it requires strengthening professional development of teachers. Generally, teachers' professional development will greatly promote the improvement of their qualities and professional skills, and thus facilitate national talent training and truly realize development of the country through science and education. Narrowly, teachers' professional development brings continuous enhancement of their working enthusiasm and subjective initiative, and plays an important promoting role in good academic atmosphere on campus. Under active motivation of teachers, students could learn more efficiently, and thus college teaching level can be improved.

\section{Main problems in professional development of college teachers}

\section{Blank space in management departments' understanding of professional development}

At present, Chinese college management departments often adopt simple evaluation of scientific research achievements combined with evaluation of students' academic achievements for evaluation of teachers' teaching results, and there is a serious phenomenon that titles are awarded according to seniority. As a result, teachers would increase the number of papers published by all manner of means in order to get good evaluation results, and carry out simple and dull cramming education in strict accordance with specified teaching tasks with only one purpose: make students get high scores in examination. This greatly limits innovation education of college teachers, especially middle-aged and young teachers. Moreover, college management departments often position their functions in teachers' performance evaluation and employment, while ignoring training and encouragement of teachers' innovativeness and diversified development, which greatly restricts teachers' play of subjective initiative.

\section{Teachers' inadequate understanding of their professional development}

Teachers have also inadequate understanding of professional development, mainly reflected in: on the one hand, most teachers are not liberated from traditional teaching ideas and concepts, and still observe all rules and regulations traditionally towards teaching, lack necessary understanding of the core of modern educational ideas and modern teaching thoughts, have not clear positioning of their professional development, carry out labor repeatedly year after year and day after day, combined with heavy tasks brought by enrollment expansion to teaching of college teachers in recent years, and thus have no time for teaching reform and improvement of professional development; on the other hand, teachers are subject to various evaluation indexes of college management departments, and have to spare a lot of energy to complete scientific investigation tasks, and would have weakened consciousness of professional development as time goes by. Almost all teachers repeat annual teaching without any individuality.

\section{Lack of correct methods in training for teachers}

With promotion of quality-oriented education actively and educational reform over many years, teachers' induction training has made considerable progress and brilliant achievements. However, a fact that we shall face is that: due to lack of correct methods, training is far from enough for needs of educational development, which is reflected as: (1) training is limited in some courses, training classes and exchange meetings etc with too short time limit, and thus is far from enough to meet growing needs of professional development; (2) training lacks necessary pertinence, and current trainings are mostly the same, while teachers need to train and cultivate various content and skills at different stages of professional development; and (3) training method is basically classroom, and 
teachers receive infusion of training passively like students, while ignoring rich creativity and individual subjective initiative, and subsequently they would also copy and repeat cramming education in their own classrooms, which is not conducive to improvement of their abilities or comprehensive development of students.

\section{Too narrow way of professional development}

Teachers' professional development covers their long-term planning of ability improvement and future professional development goals, based on which they could have corresponding exercise and change of emotion, knowledge structure and ability. However, today's college management departments focus more on evaluation of qualification, followed by constraints of various soft and rigid indexes, which have neither guided nor promoted teachers' profession, but play a negative limiting role. For teachers at different stages, for instance, new teachers may need guidance and encouragement from colleges, in order to adapt to colleges and be integrated into college development as soon as possible, while teachers who have taught for a long time are more eager to enhance teaching methods and their knowledge and abilities, and so colleges shall give enough support and recognition in this regard. However, at current stage, completion of evaluation tasks and acquisition of title promotion are still a wide gap that teachers can hardly overcome, so that they have to give up their own professional development and spend more time on title evaluation, after all this is directly related to their remuneration and induction evaluation so as not to be eliminated in evaluation.

\section{Corresponding strategies for professional development of college teachers}

\section{Fully recognize the importance of modern professional development}

As transmitters of human civilization, teachers have main work of imparting knowledge and educating people in their professional career. On the one hand, "human" is the most complicated variable, requiring teachers to be flexible necessarily and teach according to students' aptitude, and on the other hand, knowledge update speed is being accelerated in this era of information explosion. This objectively requires teachers to improve constantly and supplement knowledge and skills in order to meet requirements of imparting knowledge and educating people in modern education.

\section{Carry out professional planning rationally and effectively}

Teachers shall have good professional skills and knowledge level as well as a great universal heart. College teachers shall fully recognize that they shall train their mental state constantly as teachers besides pursuing material benefits and professional titles since they have chosen this profession. This would guide teachers to establish more lofty ideals, fully recognize their characteristics, and plan their development in the long run, so as to develop their interests and hobbies, greatly liberate their potential, increase enthusiasm for their posts, learn actively, dare to carry out innovation and promote professional development.

\section{Enrich training ways and carry out training scientifically}

Colleges are dominant in training, and implementation of various trainings depends on full support from colleges. Thus, colleges shall give full play to the guiding role, enrich training ways and carry out professional development training for teachers scientifically. With reference to foreign advanced experience and achievements in this regard, the following aspects worth reference in relevant working practice: (1) clear objects and rational training, treat differently in full accordance with teachers' individual differences based on actual condition of existing teacher structure. According to different actual needs of teachers, for instance, some hope to enhance teaching skills and methods while some hope to increase teaching knowledge and solve actual problems, classification shall be carried out scientifically, gather those with the same needs and conduct unified training according to themes of training courses and actual needs of each teacher. (2) Promote exchanges and communication among teachers. Colleges shall pay close attention to common problems in teaching, and special research groups can be set up to organize teachers to conduct active communication and exchanges about centralized and many problems in forms that commonly include: mutual class attendance and observation and communication in small groups etc. Modern education practice researches indicate that: mutual observation and communication among 
teachers are a very efficient communication method that can promote teachers to learn advanced methods effectively and improve their own teaching while seeing insufficiencies of colleagues. Traditional teaching often emphasizes efforts that individuals make for continuous promotion and completion of evaluation, while ignores communication and exchanges on teaching and fails to give full play to collective forces. Thus, colleges shall guide actively, promote mutual help and cooperation among teachers and promote overall improvement.

\section{Build a wide platform for teachers' professional development}

Professional development of college teachers cannot be separated from strong support of the outside environment, and the author suggests that: (1) colleges shall firstly play a positive guiding role, carry out field investigation and survey of current condition of teachers' professional development, study on solutions to current problems, put forward overall development plans and training plans, and in particular, pay attention to construction of a scientific teacher evaluation system, guide more scientifically and effectively, and try to make it fair, just and rational. Guide cultivation of teachers' professional development, get rid of traditional practice of top priority of titles, liberate teachers' shackles of professional development, and maximize the release of teachers' personal potential. (2) Provide more consulting opportunities for teachers' professional development. Invite more well-known experts and research institutes in field of professional development planning and education to provide teachers with excellent professional development consulting services. Reduce rigid evaluation, and give more humanistic care. For a long time, education management departments get used to work method of oppressive rigid evaluation, which greatly restricts teachers' subjective initiative so that teachers don't dare to show their individual talent and personality. Thus, colleges shall make changes actively, change rigid evaluation into humanistic care, give priority to encouragement and promote enhancement of teachers' teaching enthusiasm.

\section{Conclusions}

College teachers determine cultivation effects of high-quality talents directly, and their professional development ensures the core of teaching quality. In particular, the rise of current information technology and new teaching model of network multimedia brings unprecedented challenges to teaching of college teachers, and thus it has been urgent to improve teachers' comprehensive qualities. This requires education management departments, colleges and teachers etc to act jointly, strengthen guidance, form joint forces, promote rational planning of teachers' professional career and achieve greater development.

\section{References}

[1] Lin Jie, Li Ling. The Definition and Strategies of Faculty's Professional Development [J]. University Education Science, 2006, (01).

[2] Hu Yibo. The Connotation, Stage and Characteristics of Local College Teacher Professional Development [J]. Meitan Higher Education, 2008, (11).

[3] Li Xiuli. Thought on Self-improvement and Self-enhancement of Young College Teachers at Initial Professional Stage [J]. Time Education, 2009, (01).

[4] Bao Wei, Wang Jiaying. Pressure in the Tower of Ivory [J]. Peking University Education Review, 2012, (01).

[5] Wang Ming. Current Situation and Countermeasures of Professional Development of Chinese College Teachers [J]. Southern Periodicals, 2009, (03). 